\title{
HIV Risk Behaviour in Irish Intravenous Drug Users
}

\author{
A. Dorman, E. Keenan, C. Schuttler, J. Merry, J. J. O'Connor \\ The Drug Treatment Centre Board, Trinity Court, 30/31 Pearse Street, Dublin 2.
}

\begin{abstract}
The aim of the study was to measure HIV prevalence and risk behaviour in 185 Irish Intravenous Drug Misusers. Information was obtained by application of a standardised WHO questionnaire covering HIV risk behaviour in the preceding 6 months. HIV serostatus was obtained by saliva/blood sample testing.

One hundred and 3 (55.7 per cent) shared and 114 (61.6 per cent) lent used injecting equipment in the previous 6 months. 97 (94.2 per cent) of those who shared always cleaned the needles before use but only 48 ( 49.5 per cent) of these always cleaned in an efficient manner.

One hundred and 14 (79.2 per cent) males and 28 (68.3 per cent) females reported heterosexual activity in the preceding 6 months. On examination sexual risk behaviour was found to be high. 50.5 per cent of males and 63 per cent of females never used condoms with regular partners. 32.6 per cent of males never used condoms with casual partners.

The large majority of partners of male I.D.U'.s (both regular and casual) were non injectors. Therefore there is potential for sexual spread of HIV into the non-injecting heterosexual population. Conversely the vast majority of partners of female IDU's were injectors. This suggests that female IDU's are at higher risk of HIV infection than their male counterparts.
\end{abstract}

HIV prevalence in the study group was 8.4 per cent. Implications of results for future intervention are discussed.

\section{Introduction}

In Europe injecting drug users are the largest group of registered cases of Aids ${ }^{1}$. While HIV infection among Intravenous Drug Users is mainly transmitted through syringe sharing it is primarily a sexually transmitted disease ${ }^{2}$.

Drug injectors have reduced their sharing of injecting equipment in response to a wide variety of Aids prevention programmes including syringe exchanges and substance misuse treatment programmes but changing sexual risk behaviour has been considerably more difficult ${ }^{3}$. Various studies have shown a reduction in needle sharing and intravenous use over time $e^{4,5,6,7}$. Sexual behaviour does not appear to have changed with the advent of H.I.V, with the majority of injecting drug users being-sexually active and condom use remaining low $^{8,9,10}$. Limited changes in sexual risk behaviour have been noted though in some studies ${ }^{11,12}$.

A high proportion of drug injector's partners (especially partners of male injectors) are non-injectors and concern has been raised about the significant sexual risk of H.I.V. transmission to this group and the lack of care/counselling this group is receiving ${ }^{13,9}$.

In the Republic of Ireland Intravenous Drug Abuse is the largest risk category for HIV with 49 per cent of cumulative HIV positive cases being injecting drug users ${ }^{14}$. There has been a major expansion of treatment services in the 1990s in Ireland upon the publication of The Government Strategy to Prevent Drug Misuse $1991^{15}$ and National Aids Strategy Committee report $1992^{16}$.

Treatment places and syringe exchanges have increased and there is easy availability of condoms. In 1991 Johnson found a HIV prevalence of 14.8 per cent amongst attenders at a Dublin needle exchange with high levels of unsafe injecting and sexual risk behaviour ${ }^{17}$. Other recent HIV

Correspondence to:

Dr. Arthur Dorman

This article is a reproduction of that published in: Irish Journal of Medical Science, 166(4), October 1997, pp.235-238. Pagination may not match that of original. 
prevalence figures in the British Isles are 12.8 per cent in London, 1.8 per cent in Glasgow and 20.4 per cent in Edinburgh ${ }^{8,18}$.

This study reports on HIV prevalence and injecting and sexual risk behaviour in a group of Dublin I.D.U.'s. Implications and problems for future intervention are discussed.

\section{Method}

The study was undertaken as part of an ongoing World Health Organisation (WHO) multinational research initiative.

The sample comprised 185 intravenous drug users (I.D.U.) obtained from a variety of different sources. An I.D.U. was defined as having injected drugs at least once in the 2 months before interview. To ensure that a representative sample of intravenous drug users was obtained, the sample consisted both of in-treatment and out of treatment groups. I.D.U.'s were recruited irrespective of H.I.V. status.

The subjects recruited were then interviewed by a trained interviewer using a standardised WHO questionnaire. The interviews lasted approximately 90 minutes and all questions related to behaviour in the proceeding 6 months. Questions concerned HIV risk behaviour in terms of needle sharing (i.e. using a needle or syringe already used by somebody else), lending, cleaning, sexual behaviour, condom use and sexual partners.

Blood and saliva samples were obtained for the purposes of anonymous HIV testing. Informed consent was obtained from all subjects for participation in the study.

\section{Results}

Sample characteristics - The 185 subjects recruited comprised 100 "in treatment" and 85 "out of treatment" individuals. In terms of gender, 144 (77.8 per cent) were male and 41 (22.2 per cent) female. Their mean age was $24 \mathrm{yr}$ and mean age of first injecting was $18 \mathrm{yr}$ of age. One hundred and 70 (91.9 per cent) were unemployed, 109 (58.9 per cent) relied mainly on illegal income to support their habit and 124 (67.0 per cent) had a history of imprisonment.

Needle \&. Syringe Sharing - Over half the respondents, 103 (55.7 per cent), reported sharing used injecting equipment in the proceeding 6 months. A supplementary question then asked about lending injecting equipment and 114 (61.6 per cent) of the subjects reported giving their own used needle to another I.D.U. within the last 6 months.

For those I.D.U. who had shared used injecting equipment additional questions were asked related to the frequency of sharing and cleaning such needles before use (Table I)

TABLE I

Frequency of sharing used equipment and cleaning equipment before use

$$
\mathrm{N}=103
$$

How often shared used equipment

Always

Usually

Half the time

Sometimes

D.K/D.R.

How often cleaned before use

Always

Usually

Half the time

Sometimes

Never

D.K.

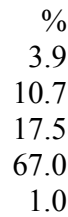

$\begin{array}{rr}\mathrm{N} & \% \\ 4 & 3.9 \\ 11 & 10.7 \\ 18 & 17.5 \\ 69 & 67.0 \\ 1 & 1.0\end{array}$

$\begin{array}{rr}\mathrm{N} & \% \\ 7 & 94.2 \\ 2 & 1.9 \\ 0 & 0.0 \\ 3 & 2.9 \\ 1 & 1.0 \\ 0 & 0.0\end{array}$


Thus 97 (94.2 per cent) of I.D.U.'s who shared injecting equipment reported that they always cleaned it prior to use. However 49 (50.5 percent) of these I.D.U's were not always cleaning in an efficient manner (i.e. bleach and boiling water). See Table II.

TABLE II

Cleaning method for those who always clean

$\mathrm{N}=97$

\begin{tabular}{lcc}
\hline & $\mathrm{N}$ & $\%$ \\
Always Efficient & 48 & 49.5 \\
Not Always Efficient & 49 & 50.5 \\
\hline
\end{tabular}

Sexual Risk Behaviour - Respondents were asked about sexual activity in the preceding 6 months. From the 144 males, 114 (79.2per cent) reported heterosexual activity and 30 (20.8 per cent) reported no sexual activity. For the 41 females 28 (68.3 per cent) reported heterosexual activity, 12 (29.3 per cent) reported no activity and 1 ( 2.4 per cent) reported prostitution. There was no reported homosexual activity.

Those subjects reporting heterosexual activity were then asked about their partners, whether they were regular or casual. A regular partner was defined as someone with whom they had been in a sexual relationship with for at least three months. Ninety-two ( 80.7 per cent $)$ males had one regular partner in the preceding 6 months and 1 ( 0.9 per cent $)$ male had two regular partners. Forty-six ( 40.4 per cent) males had casual partner(s) in the preceding 6 months. Twentysix (92.9 per cent) females had one regular partner in the preceding 6 months and 4 (14.3 per cent) had casual partner(s)

\section{Condom Use}

Table III shows condom use with partners. 50.5 per cent of males and 63 per cent of females never used condoms with regular partners. Only 20.4 per cent of males always used condoms with regular partners.

When asked about condom use with casual partners the rate was somewhat improved. 32.6 per cent of males never used condoms with casual partners and 23.9 per cent always used condoms with casual partners. However for the female I.D.U's too much cannot be extrapolated from the data as only 4 females reported casual partners.

\section{Injecting Status of Sexual Partner}

In looking at injecting status of sexual partner, information was only available on 104 of the 114 males who were heterosexually active and 26 out of the 29 females who were heterosexually active.

Out of these, 83 males and 24 females reported regular partners in the proceeding 6 months ( 1 male had 2 regular partners). 23.8 per cent ( 20 out of 84 ) of the regular partners of male IDU's were injectors while 91.7 per cent (22 out of 24) of the regular partners of female IDU's were injectors. Female IDU's were significantly more likely to have a regular partner who also injects $(\mathrm{X}=39.6 \mathrm{P}<0.01)$

Turning our attention to casual sexual partners in the proceeding 6 months, 41 males and 4 females reported casual partners. In view of the small numbers of females reporting casual partners little information can be obtained from comparing the male and female I.D.U.'s. However for the 41 male I.D.U.'s, 13 had injecting casual partners and 34 had non injecting casual partners (patients may have more than one casual partner).

From this data we therefore observe that the male intravenous drug users are commonly involved in sexual relationships with non-injecting partners on both a regular and a casual basis. The female is much less likely to have a regular partner who does not inject drugs. 
One hundred and eighty out of 185 IDU's agreed to HIV testing. The HIV prevalence was 8.4 per cent.

TABLE III

Condom Use with partners

\begin{tabular}{|c|c|c|c|c|c|c|c|c|}
\hline \multirow[b]{3}{*}{ Frequency } & \multicolumn{4}{|c|}{ Regular } & \multicolumn{4}{|c|}{ Casual } \\
\hline & Male & $(\mathrm{N}=93)$ & Female & $(\mathrm{N}=27)^{*}$ & Male & $(\mathrm{N}=46)$ & & ale $(\mathrm{N}=4)$ \\
\hline & $\mathrm{N}$ & $\%$ & $\mathrm{~N}$ & $\%$ & $\mathrm{~N}$ & $\%$ & $\mathrm{~N}$ & $\%$ \\
\hline Always & 19 & 20.4 & 4 & 14.8 & 11 & 23.9 & 2 & 50 \\
\hline Usually & 5 & 5.4 & 0 & 00.0 & 5 & 10.9 & 0 & 0 \\
\hline Half the time & 4 & 4.3 & 0 & 00.0 & 6 & 13.0 & 0 & 0 \\
\hline Sometimes & 18 & 19.4 & 6 & 22.2 & 9 & 19.6 & 0 & 0 \\
\hline Never & 47 & 50.5 & 17 & 63.0 & 15 & 32.6 & 2 & 50 \\
\hline
\end{tabular}

\section{Discussion}

Numerous studies have shown a reduction in injecting risk behaviour in I.D.U.'s since the recognition of HIV/ AIDS. The results of this study still show high levels of sharing and lending of used injecting equipment in the previous 6 months. It is difficult to compare these results with Johnson (1991) as the time period over which risk behaviour was assessed was shorter. Their study noted that 47.4 per cent lent used needle and 48.7 per cent shared used needles in the previous 28 days ${ }^{17}$.

To their credit almost all I.D.U's who shared used equipment attempted to clean it before use but it is of concern that only approximately half always cleaned efficiently. A similar trend was noted in Glasgow and London I.D.U.'s ${ }^{8}$. Because of the high level of inefficiency in cleaning we would feel that I.D.U's should only receive one message regarding reducing injecting risk behaviour i.e. only use new injecting equipment.

As in previous studies heterosexual activity is high with the majority of I.D.U.'s being sexually active in the preceding 6 months ${ }^{9}$. Condom use was low, particularly with regular partners. Half the males and almost two thirds of females never used condoms with their regular partners while a third of males never used condoms, .with casual partners. Therefore the potential for sexual transmission of HIV is high.

Previous studies have shown low condom use in I.D.U's and noted that changing sexual risk behaviour has been more difficult to achieve than needle sharing behaviour ${ }^{2}$. Johnson et al found that in Dublin needle exchange attenders in 199129.5 per cent never used condoms and 23.9 per cent always used condoms in heterosexual activity in the previous 28 days ${ }^{17}$.

A large majority of the partners of male I.D.U's (both casual and regular partners) were non injectors. There is therefore the potential for sexual mixing ofI.D.U.'s and the non injecting heterosexual population where unprotected sex may be the only risk factor. Moss suggested that drug users are the source of at least three quarters of cases of heterosexual transmission of H.I.V. in the U.S. ${ }^{19}$ In the U.K. a drug injecting partner is reported in over 60 per cent of first generation cases of heterosexual transmission of H.I.V. ${ }^{20}$. With low condom use in the group as a whole one has to be concerned with the potential of H.I.V. transmission to the non-injecting heterosexual population (especially females) in Ireland. Previous research has highlighted this concern ${ }^{8}$. The high levels of heterosexual risk behaviour and high numbers of non- injecting partners has prompted much comment in recent times and it has been suggested that drug treatment agencies are not fully addressing sexual risk behaviour in I.D.U's and partners and therefore a broader outreach approach should be implemented ${ }^{2,9}$. White pointed out that non using partners of I.D.U.'s do not generally receive care from drug treatment or other agencies and it is therefore 
likely that issues surrounding their sexual health are not addressed13. It would be important to debate the situation within Irish treatment settings.

Male injectors are likely to be in a sexual relationship with non injecting women while injecting women are more likely to be in a relationship with injecting men ${ }^{2}$. The results of this study are in keeping with this. This suggests that female I.D.U's are at greater HIV risk than their male counterparts ${ }^{21}$. Saxon noted that having a sexual partner who is also an I.D.U. increases the risk for I.V. use and sharing equipment and makes risk reduction less likely ${ }^{5}$. Therefore in treatment and counselling female I.D.U.'s should perhaps be focused upon as a group particularly prone to HIV risk behaviour.

The HIV prevalence in the group was 8.4 per cent which is lower than the figure of 14.8 per cent obtained by Johnson in Dublin needle exchange attenders in $1991^{17}$. One reason for this lower prevalence would be an expected fall in risk behaviour since the introduction of extensive harm reduction programmes to Dublin in the early 1990's. Unfortunately it is difficult to compare the risk behaviour rates in the two studies as the time period over which risk behaviour was measured was different - the preceding 28 days in Johnson's study compared with the preceding 6 months in the present study. The prevalence rate in our study may be a better estimate of HIV prevalence in Dublin as the sample size was larger than Johnson's and the IDU's were recruited from a number of sources both in treatment and out of treatment.

The level of HIV prevalence with the levels of risk behaviour show the potential for spread of H.I.V. and indicates that much work is yet to be done to attempt to minimise the spread of HIV within Ireland.

\section{References}

1. European Centre for the Epidemiological Monitoring of Aids. Quarterly Report No 47. HIV/AIDS Surveillance in Europe. 1995/3.

2. Donoghue, M. Sex, HIV, and the injecting drug user. British Journal of Addiction. 1992; 87: 405-416.

3. Des Jarlais, D. C. The first and second decades of AIDS among injecting drug users. British Journal of Addiction. 1992; 87:347-353.

4. Frisher, M., Bloor, M. et al. Reduction in Needle sharing among community wide samples of injecting drug users. International Journal of STD \& AIDS. 1992; 3: 288-290.

5. Saxon, A. J., Calsyn, D. A., Jackson, T. R. Longitudinal changes in injection behaviours in a cohort of injection drug users. Addiction 1994 : 89, 191-202.

6. Nicolosi, A., Molinari, S. et al. Positive modification of injecting behaviour among intravenous heroin users from Milan and North Italy 1987-1989. British Journal of Addiction 1991:86: 91-102.

7. Donoghue, M. C., Stimson, G. V. et al. Changes in HIV risk behaviour in clients of syringe exchange schemes in England and Scotland. AIDS 1989; 3(5): 267-272.

8. Rhodes, T. J., Bloor. M. J. et al. HIV prevalence and HIV risk behaviour among injecting drug users in London and Glasgow. AIDS CARE. 1993 Vol. 5(4): 413-425.

9. Rhodes, T., Donoghue, M. et al. Sexual behaviour of drug injectors in London: Implications for HIV transmission and HIV prevention. Addiction 1994; 89: 1085-1096.

10. Klee. H., Faugier. J. et al. Sexual Partners of injecting drug users : The risk of HIV infection. British Journal of Addiction. 1990; 85: 413-418.

11. Skidmore, C. A., Robertson, J. R., Roberts, J. J. K. Changes in HIV risk-taking behaviour in intravenous drug users: a second follow-up. British Journal of Addiction. 1989; 84: 695696. 
12. Donoghue, M. C., Stimson, G. V., Dolan, K .A. Sexual behaviour of injecting drug users and associated risks of HIV infection for non-injecting sexual partners. AIDS CARE 1989 1(1): 51-58.

13. White, D., Phillips, K. et al. Sexual issues and condom use among injecting drug users. AIDS CARE. 1993; 5(4): 427-437.

14. Virus Reference Laboratory, University College Dublin. Virus Alert: Issue 3/95.

15. Department of Health (Ireland) - Government Strategy To Prevent Drug Misuse. May 1991.

16. Aids Strategy Committee Report - 1992 Department of Health (Ireland).

17. Johnson, Z., O'Connor, M., et al. Prevalence of HIV and associated risk behaviour in attendees at a Dublin needle exchange. Addiction 1994; 89: 603-607.

18. Bath, G. E., Dominy, N. et al. Injecting drug users in Edinburgh - Fewer drug users share needles (Letter). British Medical Journal 1993; 306(6889): 1414.

19. Moss, A. R. Aids and intravenous drug use: The real heterosexual epidemic. British Medical Journal 1987; Vol. 294: 389-390.

20. Evans, B. G., Noone, A. et al. Heterosexually acquired HIV-1 infection: Cases reported in England, Wales and Northern Ireland. 1985-1991, in Communicable Disease Report, Public Health Laboratory Service. 1992; 2(5).

21. Freeman, R. C., Rodriguez, G. M., French, J. F. A comparison of male and female intravenous drug users' risk behaviours for HIV infection. American Journal of Drug and Alcohol Abuse. 1994; 20: 129-57. 